\title{
Resistivity, ESR, and Radiation Shielding Properties of the Volcanic Rock Materials
}

\author{
Çiğdem Nuhoğlu, ${ }^{1}$ Mucip Tapan, ${ }^{2}$ Mustafa Okutan,, ${ }^{1}$ Süreyya Aydın, ${ }^{1}$ Zeynel Yalçın, \\ Orhan İçelli, ${ }^{1}$ H. Birtan Kavanoz, ${ }^{1}$ and Salim Orak ${ }^{3}$ \\ ${ }^{1}$ Department of Physics, Faculty of Arts and Sciences, Yildiz Technical University, 34220 Istanbul, Turkey \\ ${ }^{2}$ Natural Resources of Van Lake Basin Research and Application Center, Yüzüncü Yıl University, Zeve Campus, 65080 Van, Turkey \\ ${ }^{3}$ Department of Mathematics, Faculty of Arts and Sciences, Istanbul Commerce University, Üsküdar, 34660 İstanbul, Turkey
}

Correspondence should be addressed to Orhan İçelli; orhanicelli@gmail.com

Received 24 December 2013; Accepted 28 January 2014; Published 6 March 2014

Academic Editor: Jörg Fink

Copyright (C) 2014 Çiğdem Nuhoğlu et al. This is an open access article distributed under the Creative Commons Attribution License, which permits unrestricted use, distribution, and reproduction in any medium, provided the original work is properly cited.

Pumices have been used in cement, concrete, brick, and ceramic industries as an additive and aggregate material. It will be important to study pumice types by using a different tool as EPR which is a new technique for related material to be used for industrial aims. Electron spin resonance (ESR) spectra of the pumice types were taken by EMX-type spectrometer. Also, the current-voltage $(I-V)$ and surface resistivity probe stand of the thin films was studied using a four-point probe measurements. The relationship between radiation shielding properties of the pumice samples and their surface resistivity, chemical, and electrokinetic properties was evaluated using simple regression analysis. Simple regression analysis indicated a strong correlation between surface resistivity and density and $\mathrm{SiO}_{2}, \mathrm{Fe}_{2} \mathrm{O}_{3}, \mathrm{CaO}, \mathrm{MgO}$, and $\mathrm{TiO}_{2}$ content of pumice samples in this study. It is found that a correlation between determined $g$-factor by EPR spectroscopy and radiation shielding is established for pumice samples.

\section{Introduction}

Pumice is a porous, natural glass formed from volcanic activity and contains relatively high concentrations of silica, aluminum, and iron. Pumice has been used as an adsorbent and as photo catalysts in water treatment. It was selected as the catalyst in the present study because of its excellent chemical and configurable properties, such as high mechanical strength and chemical stability [1]. The performance of pumice based concrete mixtures has increased concrete resistance against seawater attack [2].

Pumice may be used in regions where radiation is effective. It can easily be used in walls and coverings of medical buildings and nuclear reactors [3].

Pumice brings many advantages due to its superior properties like its low density, high heat and noise insulation, air conditioning characteristic, easy plaster retaining, perfect acoustic feature, and elasticity in case of seismic load and behaviors. However, it may be considered as a disadvantage that it causes disintegration in concrete due to low density and due to prior water absorption and additional water absorption amount during preparation of concrete mixture and the risk related to flocculation due to contact of aggregates with cement during concrete pouring [4].

Due to the fact that these pumice types (pumice, CDS, and PTS) can be used in different applications including boron industries and building process or as a radiation shielding material, it will be important to study pumice types by using a different tool as EPR which is a new technique for related material to be used for industrial aims.

Electron paramagnetic resonance (EPR) is the resonant absorption of electromagnetic radiation by a paramagnetic particle (atom, molecule, or ion), having nonzero electronic spin due to unpaired electrons in its outer shells, and it is a very powerful nondestructive technique used for the study of the electronic structure of paramagnetic centers, for example, 


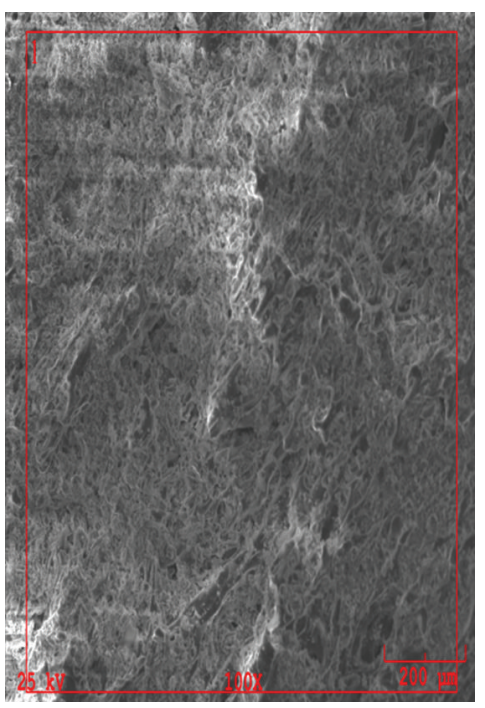

(a)

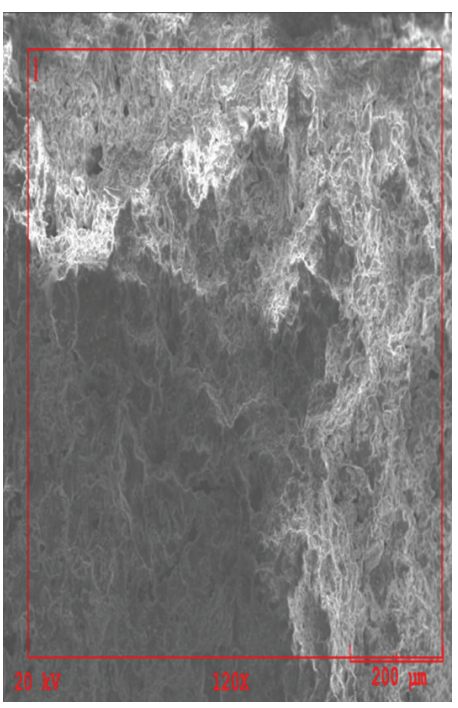

(b)

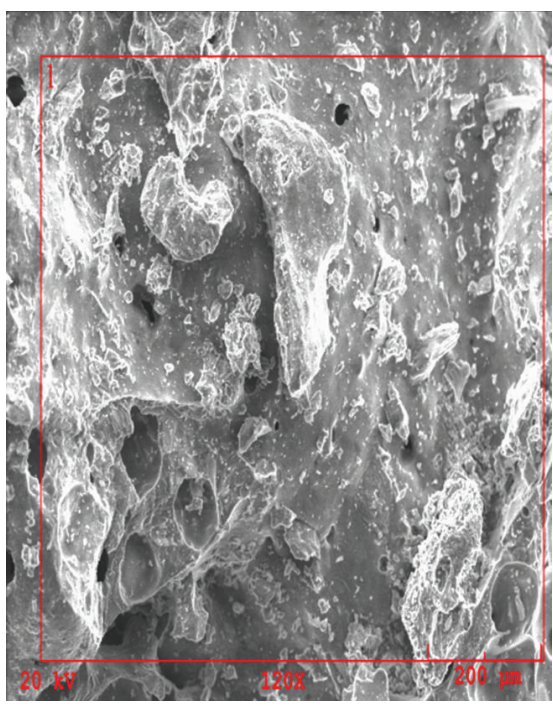

(c)

FIgUre 1: SEM images: (a) pumice, (b) PTS, and (c) CDS.

transition metal ions such as copper, chromium, and nickel in a large variety of organic and inorganic compounds. The flipping of spins induced in a paramagnetic system embedded in a static magnetic field by the absorption of the electromagnetic radiation is the physical principle behind the EPR technique. For a system with a spin $s=1 / 2$, for example, a free electron or a radical, there are two energy levels corresponding to the spin parallel and antiparallel to the static magnetic field, the latter being of lowest energy [5]. EPR spectroscopy is needed to obtain structural information about the metal binding. As seen in the literature, investigation of nonirradiated and gamma-irradiated Trommel Sieve Waste (TSW) with EPR technique has been studied. Magnetic properties of TSW and its applications were evaluated by using EPR spectroscopy [6].

\section{Experimental}

2.1. Sample Measurements. Chemical analyses of the volcanic rocks are taken by X-ray fluorescence (XRF) instrument. Operating conditions of the Philips PW-2400 XRF instrument were set at $60 \mathrm{kV}$ and $50 \mathrm{~mA}$. The compositions of the pumice samples were checked by X-ray powder diffraction. By comparing the positions of the diffraction peaks against that of the ICDD cards; the target material was identified. Loss of ignition (LOI) of the samples was measured by weighing the samples before and after heating up to $1000^{\circ} \mathrm{C}$. Lower detection limits are $0.01 \mathrm{wt} . \%$ for all element species.

Electron paramagnetic resonance (EPR) spectra of the volcanic rocks samples were taken by high sensitive conventional X-band $(9.5 \mathrm{GHz})$ Bruker EMX-type spectrometer at room temperature.

The current-voltage $(I-V)$ and surface resistivity probe stand of the thin films was studied using a four-point probe measurements Lucas Signatone System. I-V and surface resistance were measured using a Keithley 2400 Source-Meter in a four-point probe technique at room temperature.

\section{Result and Discussion}

Figure 1 shows the SEM micrographs of different volcanic rocks, pumice, PTS, and CDS. The micrographs are illustrating the microstructure characteristics. All volcanic rock samples have different sized and irregular oval shaped pores with open and filled forms. The structure of pumice with smooth surface is the same microvesicular pumice where pores are smaller than that of other volcanic rocks. The morphology of CDS sample surface is rough-looking and closed than other rocks, also all pores it's in open form.

Figure 2 shows EDS spectrums of pumice, PTS, and CDS which have different chemical compositions. These spectrums were obtained from the points that ideally characterize the volcanic rocks. As shown in Figure 2(a) pumice sample contains high amount of $\mathrm{Si}, \mathrm{Al}, \mathrm{Ca}$, and $\mathrm{K}$. High amount of $\mathrm{Si}$ and $\mathrm{K}$ in pumice is due to high amount of volcanic glass and acidic characteristic. For PTS and CDS the amount of Si is lower than pumice samples, while the amounts of $\mathrm{Ca}$ and Fe are found to be more (Figures 2(b) and 2(c)). This shows that PTS and CDS contain more mafic volcanic glass.

A new approach was introduced for the analysis of complex civil engineering problems using EPR. The capabilities of the EPR methodology were illustrated by applying it to two practical problems involving the prediction of the stability status of slopes and the compressive strength of rubber concrete [7].

EPR spectra were taken for $\mathrm{Fe}^{+}$ion. The broad EPR lines stem from strong dipolar interactions of their unpaired magnetic moments. Samples were measured using an X-band $(9.53 \mathrm{GHz})$ EPR spectrometer with modulation of magnetic field of $10 \mathrm{kHz}$. EPR spectra were measured with attention of 


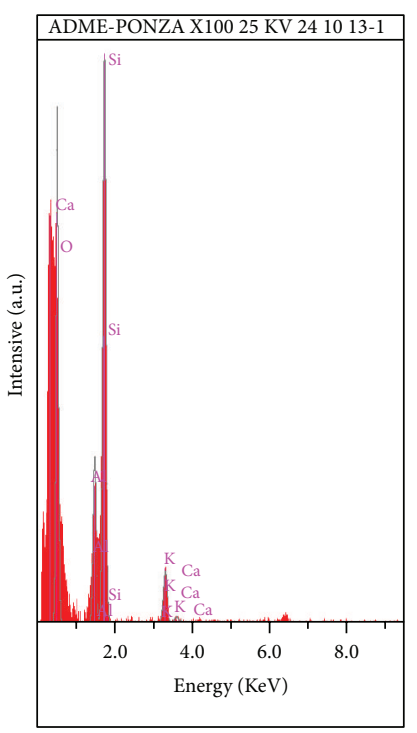

(a)

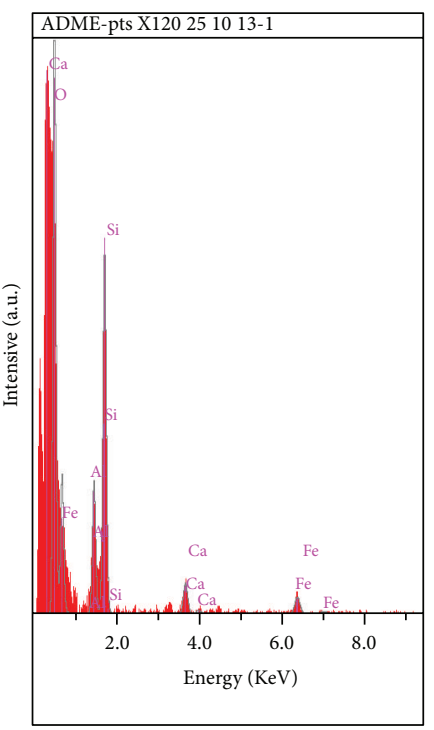

(b)

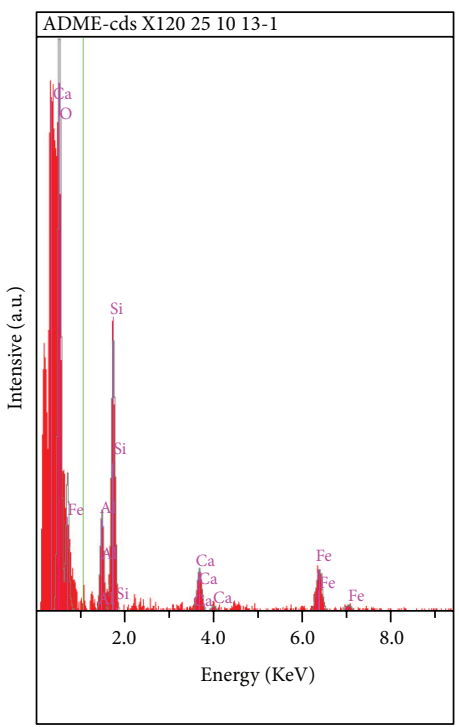

(c)

FIGURE 2: EDS analysis: (a) pumice, (b) PTS, and (c) CDS.

$23 \mathrm{~dB}$ to avoid microwave saturation of resonance absorption curves. Figure 3 shows the EPR spectra for $\mathrm{Fe}^{+}$ion at room temperature. With $S=1 / 2, I=3 / 2$ for $\mathrm{Fe}^{+}$ions with $2.15 \%$ natural abundance. $g$ factor was calculated from resonance conditions as seen in what follows:

$$
g=\frac{h \gamma}{\beta B_{r}},
$$

where $h$ is Planck constant, $\gamma$ is the microwave frequency, $\beta$ is the Bohr magnetron, and $B_{r}$ is the resonance magnetic field.

The lines were observed in these resonance absorption curves in Figure 3. Free radicals of $\mathrm{Fe}^{+}$ion are responsible for EPR lines. EPR line unresolved hyperfine structure is characteristic for free radical of $\mathrm{Fe}^{+}$ion. The $g$ value of free radical close to 2.00 confirms that the free radical and transition metal ions do have $g \approx 2$, but there are also systems which show marked deviations from this value [8].

Free radicals are generally highly unstable and have very short residence time. However, the certain free radicals have persisted for much longer duration because they were trapped in a stable cell wall matrix [9].

Based on our EPR measurements it is possible to conclude that, similarly as in the investigation of the hardening during the sol-gel processes, the presence of $\mathrm{Mn}^{2+}$ ions in the cements can be used for the characterization of the kinetic parameters of the solidification and hardening of cement slurries [10]. We have stated the possibility to conclude with EPR that the presence of $\mathrm{Fe}^{+}$ions in the CDS and PTS except for pumice can be used for the characterization of the kinetic parameters of the solidification and hardening of cement slurries.

The three lines were observed in this resonance absorption curves in Figure 3(a), while the band centered at $1500 \mathrm{G}$ $(g=4.658), 2650 \mathrm{G}(g=2.636)$, and $3350 \mathrm{G}(g=2.085)$ was shown. It was shown in Figures 3(b) and 3(c) that these spectra are typical EPR signals belonging to $\mathrm{Fe}^{+}$ion spectra, while the band centered at $3500 \mathrm{G}(g=1.996)$ and $3000 \mathrm{G}$ $(g=2.329)$. The occurrences indicate that the PTS, CDS, and pumice can be coordinating with the active sites of the pairing of the electrons.

Four-point probe technique was employed during the in-plane conductivity measurements, which were designed according to the property of the samples. The typical spot bias current $(I)$ applied with the outpoint serial contact and the voltage $(V)$ were measured with inside parallel contact system. The typical forwarded bias voltage $(V)$ and current $(I)$ characteristics obtained from the volcanic rocks are shown in Figure 4. $I-V$ curves of the samples are nonlinear at low voltage and linear at high voltage of CDS and PTS. All the curves show an intersection at low forwarded current biases $\left(1 \times 10^{-9}-100 \times 10^{-9} \mathrm{Amp}\right)$.

The surface resistivity and conductivity values are obtained by four-point probe measurement techniques. The source current $\left(I_{s}\right)$ and the measurement voltage $\left(V_{\mathrm{DC}}\right)$ values are given in Table 1 of the samples. The spot bias current which we have chosen was $8 \times 10^{-9}$ Amperes for CDS, PTS, and pumice. The values of $V-I$ responses give us the surface resistivity in Ohm-cm, when we employ $\pi / \ln 2=4.5324$ coefficient. The theory of measuring surface resistivity applies the following formula:

$$
\rho_{s}=4.5324 \frac{V}{I}
$$

where $\rho_{s}$ is the ohm-centimeter, $V$ is the volts, and $I$ is the ampere.

As seen in Table 1, looking at the surface resistance measurements, while PTS samples has the lowest resistivity and surface resistivity CDS has the highest.

As seen in Table 2, inverse correlation is confirmed between \%wt $\mathrm{Al}$ concentration and surface resistivity. 


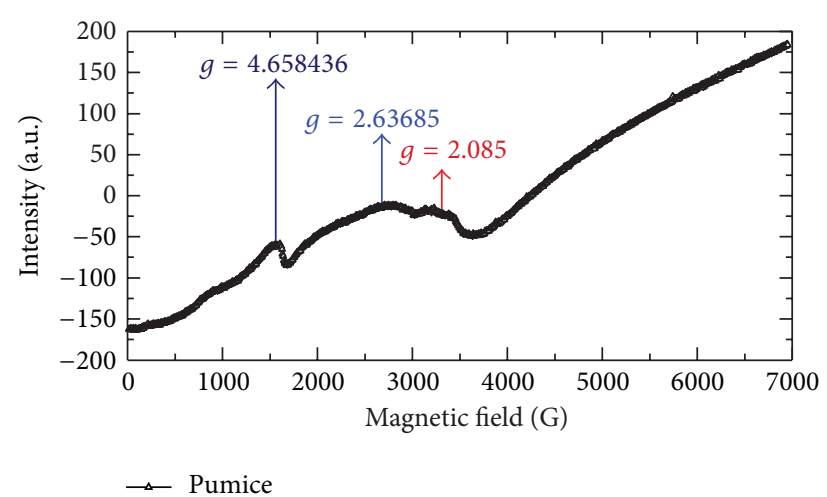

(a)

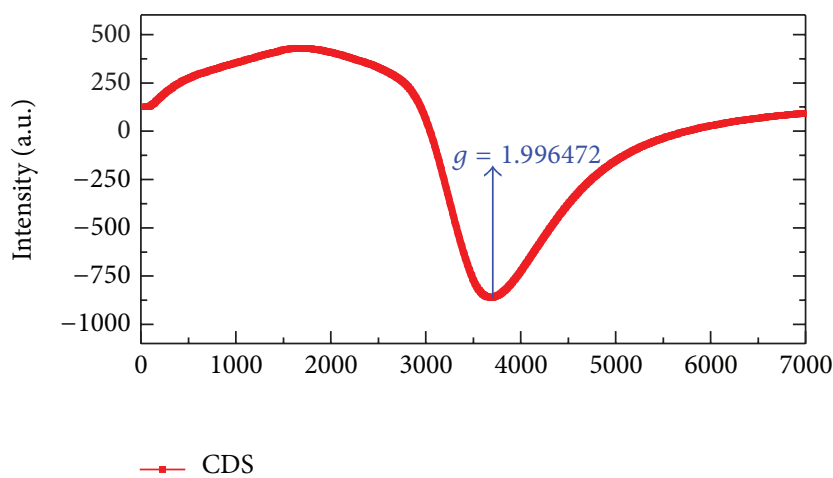

(b)

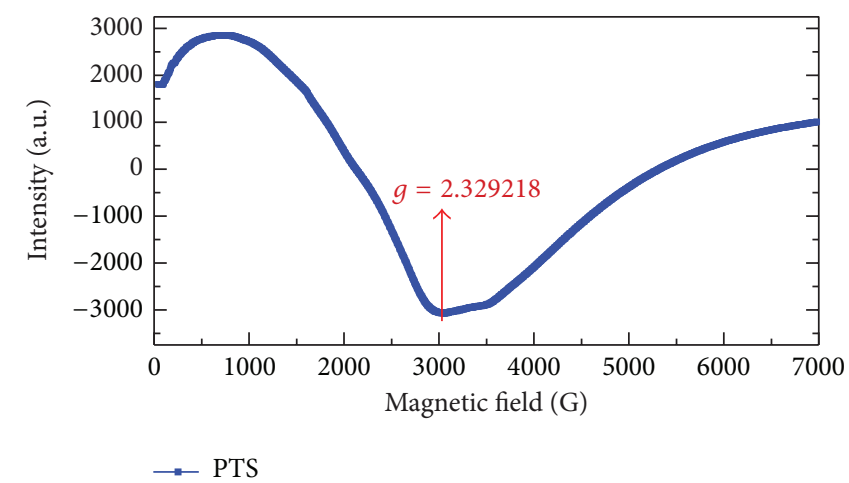

(c)

FIGURE 3: X-band EPR spectra of the volcanic rocks: (a) pumice, (b) CDS, and (c) PTS.

TABLE 1: The surface resistance measurements.

\begin{tabular}{lcccc}
\hline Samples & $I \times 10^{-9}(\mathrm{Amp})$ & $V_{\mathrm{DC}}($ Volt $)$ & $\begin{array}{c}\text { Surface resistivity } \times 10^{8} \\
(\text { Ohm-cm })\end{array}$ & $\begin{array}{c}\text { Conductivity } \times 10^{-9} \\
(\text { Ohm-cm })^{-1}\end{array}$ \\
\hline CDS & 8.04539 & 1.07199 & 6.03857 & 1.65602 \\
PTS & 8.02811 & 0.48724 & 2.75057 & 3.63561 \\
Pumice & 8.96023 & 1.14774 & 5.80514 & 1.72261 \\
\hline
\end{tabular}

Namely, \%wt Al concentration is little for CDS but surface resistivity is the highest compared to the others. Previously, a correlation between $\% \mathrm{Al}$ and resistivity was observed by habib 2012 [11].

Shielding is particularly needed for underground vaults containing transformers and other electronics that are relevant to electric power and telecommunication. The main mechanism for electromagnetic interference shielding using conductive materials is reflection. Another mechanism is absorption. The loss is due to absorption increase with increasing frequency [12].

Ramezanianpour et al. show that although in concretes with similar cementations materials different relationships can be found, but generally because of different mechanisms of compressive strength and electrical resistivity, there is no appropriate relationship between them. Consequently it is not recommended to use electrical resistivity as an indicator for evaluation of compressive strength. But SR (surface resistivity) can be used as an electrical indicator of concrete chloride penetration resistance [13]. We have recommended CDS rather than PTS and pumice as confirmed by Figure 5.

\section{Conclusion}

The elemental compositional differences are present between the volcanic rocks with energy dispersive spectrometer (EDS) measurement. EDS measurements of all the samples were made on a point which was a selected area from the SEM micrographs. EDS analysis with SEM micrographs illustrating that pore size increased with iron $(\mathrm{Fe})$ appearance and decreased with silicon $(\mathrm{Si})$ concentration in the elemental composition of samples, shown in Table 2. There is direct relation between \%wt $\mathrm{Fe}$ and compressive strength. We have known that the compressive strength increases with increasing rate of \%wt Fe. As seen in Figure 2, this state is confirmed because $\mathrm{K}$-alpha intensity of CDS is bigger than PTS and pumice. There is indirect relation between \%wt Fe 


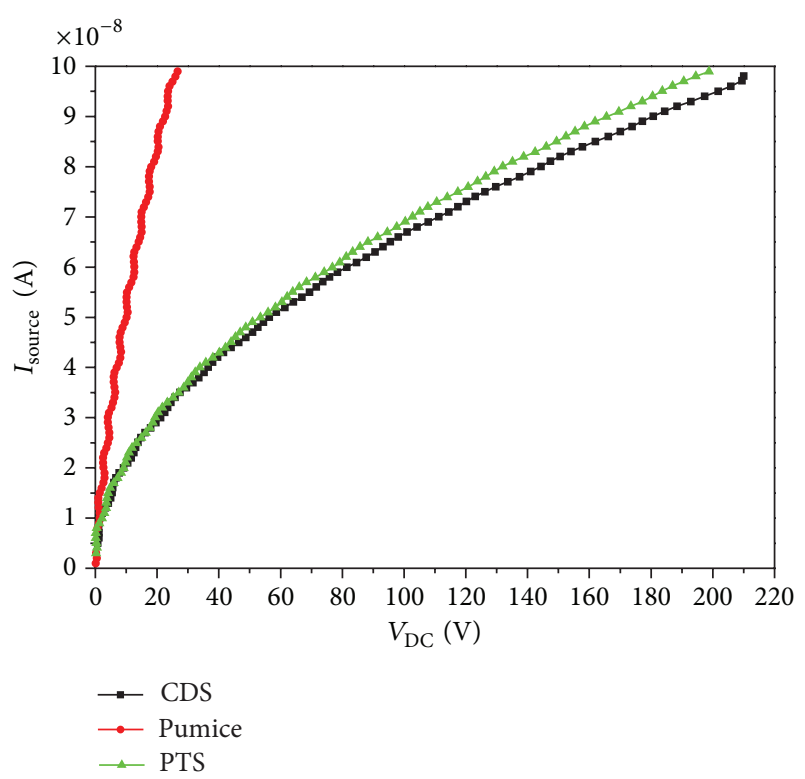

FIGURE 4: $I-V$ graph of the volcanic rocks.

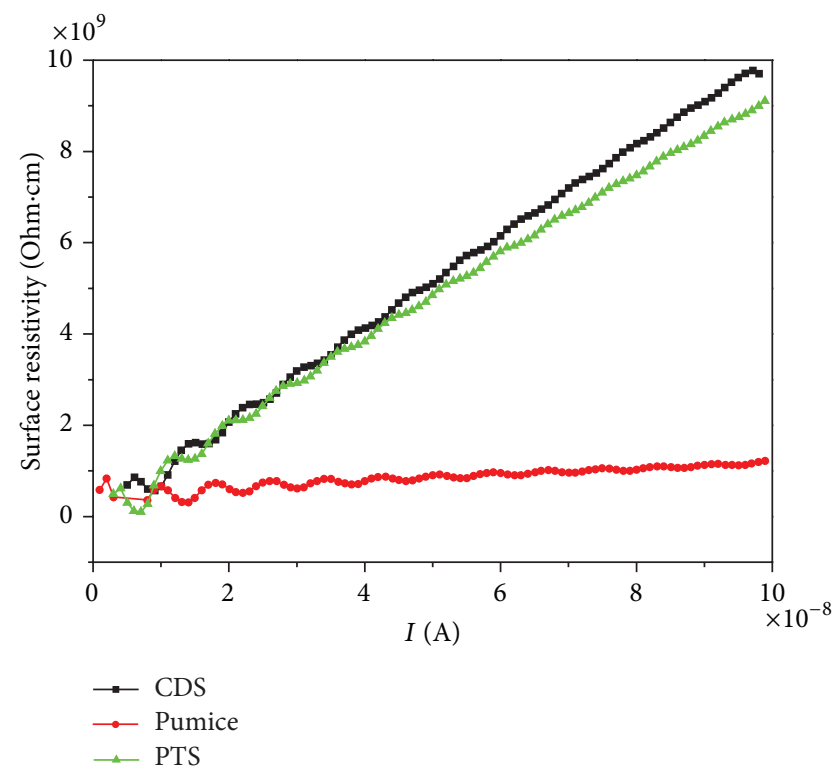

FIGURE 5: Current biases variation of surface resistivity for the volcanic rocks.

and $g$ factor. CDS which has the highest iron content has the littlest $g$ factor.

EPR studies have shown that the three lines (1500 G ( $g=$ 4.658), $2650 \mathrm{G}(g=2.636)$, and $3350 \mathrm{G}(g=2.085))$ were observed in this resonance absorption curves for pumice samples in Figure 3(a). The reason for this could be explained by the fact that pumice is a volcanic rock, has an amorphous structure, and contains more pores.

The lowest compression strength is seen in concretes containing pumice. This state may be attributed to pumice's porous structure. There is a correlation between $g$ value and compression strength and the $g$ value. The CDS sample with
TABLE 2: Qualitative and quantitative analysis for pumice types.

\begin{tabular}{lcc}
\hline & Element (line K $\alpha$ ) & Conc. (wt\%) \\
\hline \multirow{4}{*}{ Pumice } & $\mathrm{O}$ & 65.779 \\
& $\mathrm{Al}$ & 7.254 \\
& $\mathrm{Si}$ & 24.400 \\
$\mathrm{~K}$ & 2.436 \\
$\mathrm{Ca}$ & 0.130 \\
\hline \multirow{3}{*}{ PTS } & $\mathrm{O}$ & 69.187 \\
& $\mathrm{Al}$ & 7.035 \\
& $\mathrm{Si}$ & 19.077 \\
& $\mathrm{Ca}$ & 2.083 \\
& $\mathrm{Fe}$ & 2.617 \\
\hline \multirow{4}{*}{ CDS } & $\mathrm{O}$ & 69.735 \\
& $\mathrm{Al}$ & 5.681 \\
& $\mathrm{Si}$ & 14.974 \\
& $\mathrm{Ca}$ & 2.871 \\
& $\mathrm{Fe}$ & 6.739 \\
\hline
\end{tabular}

a low $g$ value (close to the free radical value) is more durable because it contains more free ions.

Pumice develops flexibility due to its high amorphous structure. The most flexible sample as PTS having a value of $g$ is the highest because of the less free ions.

As seen in Table 1, looking at the surface resistance measurements, while PTS samples has the lowest resistivity and surface resistivity CDS has the highest. If we want to establish a correlation between surface resistance measurements and $g$ factor, $g$ factor is little observed for CDS.

As a result, we have recommended CDS as an aggregator in terms of shielding rather than PTS and pumice.

\section{Conflict of Interests}

The authors declare that there is no conflict of interests regarding the publication of this paper.

\section{References}

[1] L. Yuan, J. Shen, Z. Chen, and Y. Liu, "Pumice-catalyzed ozonation degradation of p-chloronitrobenzene in aqueous solution," Applied Catalysis B, vol. 117-118, pp. 414-419, 2012.

[2] K. M. A. Hossain, "Pumice based blended cement concretes exposed to marine environment: effects of mix composition and curing conditions," Cement and Concrete Composites, vol. 30, no. 2, pp. 97-105, 2008.

[3] H. Binici, O. Aksogan, A. Hayrullah Sevinc, and A. Kucukonder, "Mechanical and radioactivity shielding performances of mortars made with colemanite, barite, ground basaltic pumice and ground blast furnace slag," Construction and Building Materials, vol. 50, pp. 177-183, 2014.

[4] S. Popovics, Concrete Materials, Properties, Specifications and Testing, Noyes Publications, Park Ridge, NJ, USA, 1992.

[5] R. P. De Carvalho, J. R. Freitas, A.-M. G. De Sousa, R. L. Moreira, M. V. B. Pinheiro, and K. Krambrock, "Biosorption of copper ions by dried leaves: chemical bonds and site symmetry," Hydrometallurgy, vol. 71, no. 1-2, pp. 277-283, 2003. 
[6] Z. Aygun, M. Aygun, B. Karabulut, and A. Karabulut, "Investigation of non-irradiated and gamma-irradiated Trommel Sieve Waste (TSW) with EPR technique," Annals of Nuclear Energy, vol. 40, no. 1, pp. 84-86, 2012.

[7] A. A. Javadi, T. P. Tan, A. S. I. Elkassas, and M. Zhang, "Intelligent finite element method and application to simulation of behavior of solids under cyclic loading," in Foundations of Computational Intelligence, vol. 205 of Studies in Computational Intelligence, pp. 317-338, 2009.

[8] J. E. Wertz and J. R. Botton, Electron Spin Resonance, Elementary Theory and Practical Applications, McGraw-Hill, New York, NY, USA, 1972.

[9] I. P. Suhasini, G. Sriram, S. R. Asolekar, and G. K. Sureshkumar, "Biosorptive removal and recovery of cobalt from aqueous systems," Process Biochemistry, vol. 34, no. 3, pp. 239-247, 1999.

[10] L. Lapčík Jr. and Z. Šimek, "Electron paramagnetic resonance study of dry cements," Cement and Concrete Research, vol. 26, no. 2, pp. 237-242, 1996.

[11] K. Habib, "Measurement of surface resistivity and surface conductivity of anodised aluminium by optical interferometry techniques," Optics and Laser Technology, vol. 44, pp. 318-321, 2012.

[12] D. D. L. Chung, "Electrically conductive cement-based materials," Advances in Cement Research, vol. 16, no. 4, pp. 167-176, 2004.

[13] A. A. Ramezanianpour, A. Pilvar, M. Mahdikhani, and F. Moodi, "Practical evaluation of relationship between concrete resistivity, water penetration, rapid chloride penetration and compressive strength," Construction and Building Materials, vol. 25, no. 5, pp. 2472-2479, 2011. 

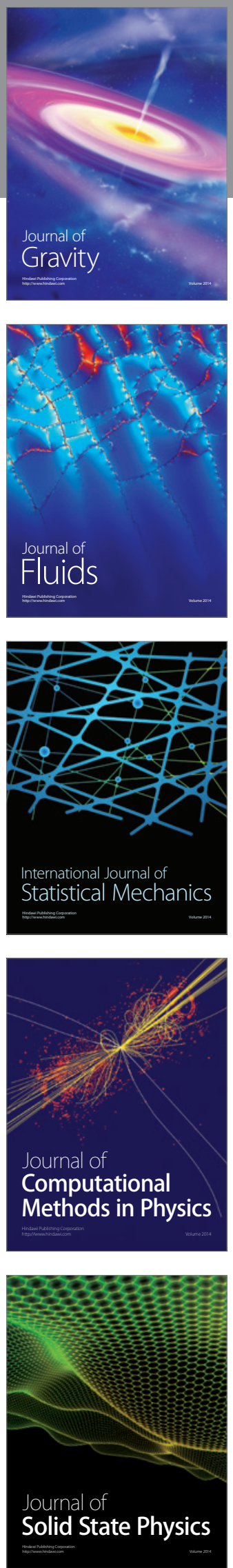

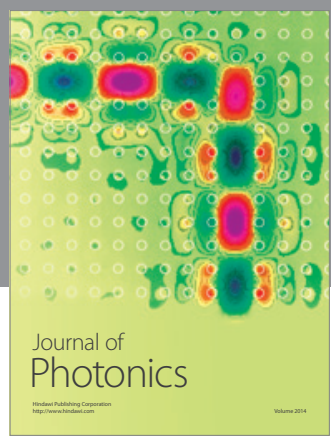

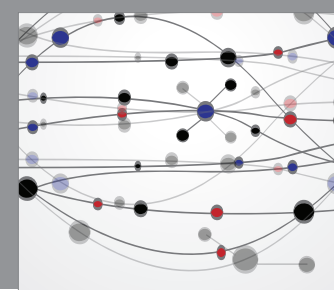

The Scientific World Journal

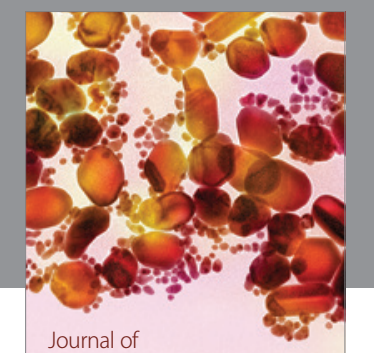

Soft Matter
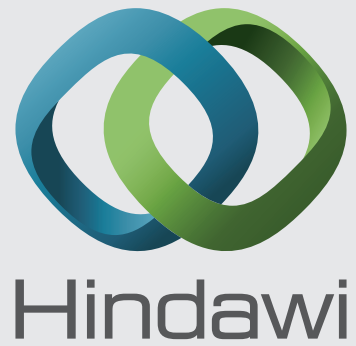

Submit your manuscripts at

http://www.hindawi.com
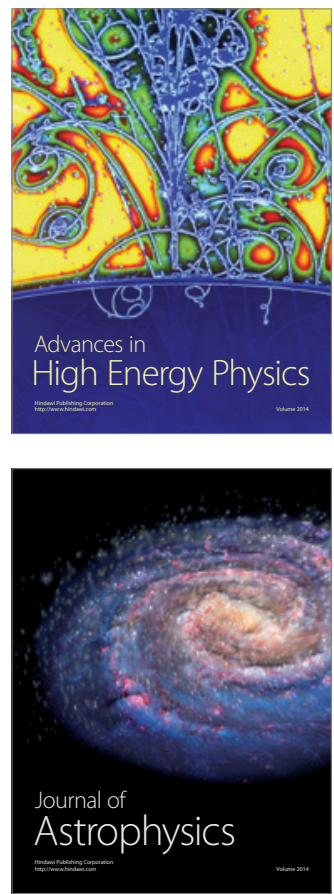
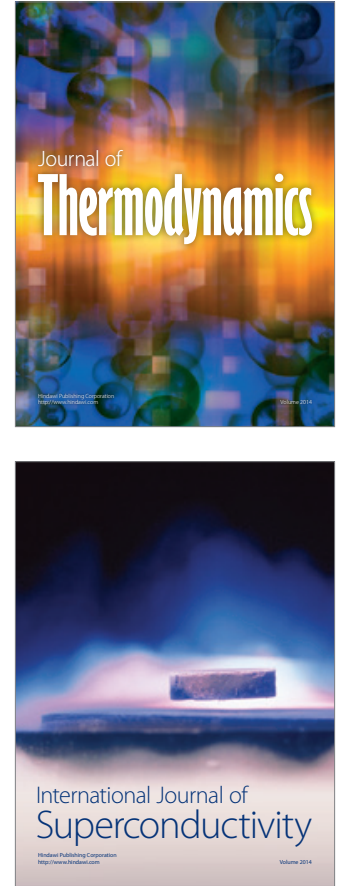
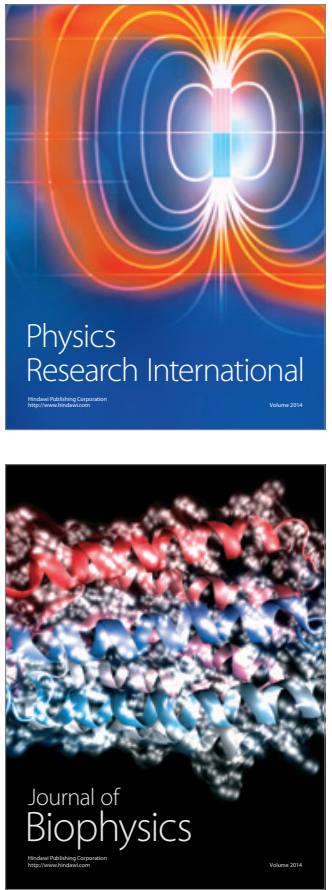
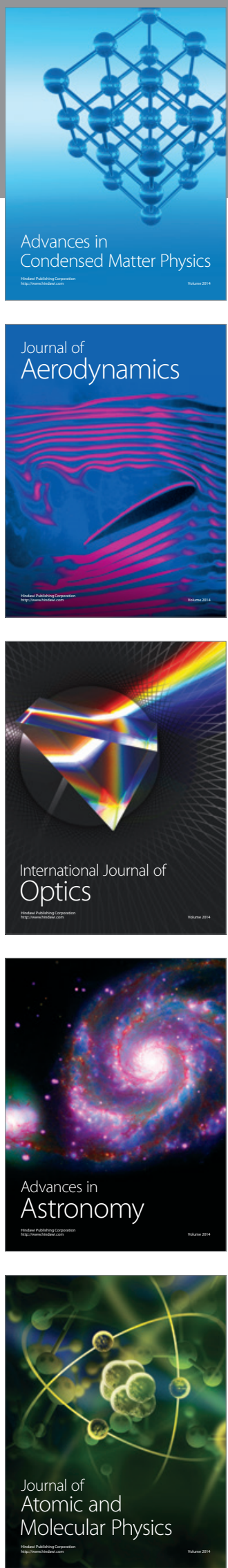